\title{
Edith Stein e a Filosofia de Platão
}

\author{
Edith Stein and Plato's Philosophy
}

(c) (1)

\section{Gilfranco Lucena Santos ${ }^{*}$}

Universidade Federal da Paraíba, João Pessoa, PB, Brasil

\section{Resumo}

Este artigo tem por objetivo pôr em evidência a conexão entre o pensamento de Stein e a filosofia de Platão. A hipótese a respeito desta relação leva em conta o esquema descrito por Stein em Ser finito e ser eterno, quando ela examina a conexão conceitual entre Aristóteles e Platão e expõe uma visão geral sobre os diferentes significados de oủoía e öv. Neste mapa conceitual, Stein nos mostra que a expressão platônica övtwৎ

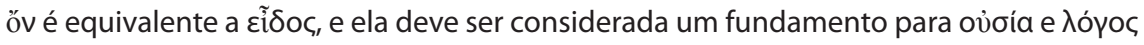
vońtoç. A análise desta conexão nos mostra que o caminho de Stein para a filosofia de Platão coloca seu projeto fenomenológico na mesma perspectiva da fenomenologia transcendental de Husserl, na qual as idealidades exercem um papel significativo para a constituição do mundo objetivo.

Palavras-chave: Edith Stein. Fenomenologia. Platão. Ontologia. Idealidade. 


\section{Abstract}

This article aims to put in evidence the connection between Stein's thinking about essentialities and Plato's Philosophy. The hypothesis of this relation takes in consideration the schema described by Stein in Finite and eternal being, when she examined the conceptual connection between Aristotle's and Plato's ontologies, and exposed an overview about different meanings of ovoía and óv. At this conceptual map, Stein shows us that the platonic

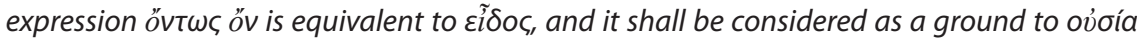

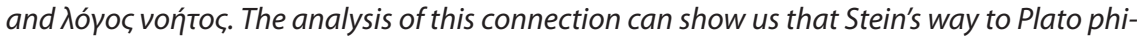
losophy put her phenomenological project in the same perspective of Husserl's transcendental phenomenology, in which idealities play a significant rule in the objective constitution of the world.

Keywords: Edith Stein. Phenomenology. Plato. Ontology. Ideality.

\section{Introdução}

Duas questões que vêm se tornando recorrentes nos simpósios e encontros realizados no Brasil, em torno do pensamento de Edith Stein, nesses últimos anos, foram assumidas na elaboração desse trabalho: uma diz respeito ao que teria levado Edith Stein a dar um passo que se diz ser "metafísico" e "além da fenomenologia". A outra diz respeito ao modo como Edith Stein considera o problema da correlação entre idealidade e o que temos denominado realidade ${ }^{1}$.

No apogeu de seu trabalho filosófico, que culminou com sua obra intitulada Ser finito e ser eterno: Ensaio de uma ascensão ao sentido do ser ${ }^{2}$, Edith Stein situa seu pensamento em torno da questão do sentido do ser, quejá para

\footnotetext{
A discussão em torno ao problema de uma posição idealista ou realista no pensamento de Edith Stein pode ser encontrada nos trabalhos do Prof. Juvenal Savian Filho: um primeiro publicado na Revista São Boa Ventura, intitulado "Idealismo e Realismo em Edith Stein" (SAVIAN FILH0, 2008, p. 11-28); outro publicado no livro que reuniu os trabalhos do último simpósio, intitulado "Edith Stein para além do debate 'idealismo versus realismo': notas de um estudo em construção" (SAVIAN FILH0, 2017, p. 203-255). Além destes, e a respeito desta mesma temática, convém também considerar o trabalho da Profa Martina Korelc, também apresentado no último simpósio, intitulado "0 debate 'idealismo versus realismo' em Husserl e Edith Stein" (KORELC, 2017, p. 161-202).

2 Em alemão, no original, Endliches und ewiges Seins; Versuch eines Aufstiegs zum Sinn dês Seins.
} 
Martin Heidegger, um de seus interlocutores no Círculo Fenomenológico de Husserl, tornara-se a questão fundamental do pensamento contemporâneo. Esta orientação do pensamento fenomenológico para a questão do sentido do ser é o motivo fundamental pelo qual Edith Stein se viu impulsionada a um retorno à filosofia medieval e à filosofia antiga, para, a partir dessas fontes, estabelecer as bases para uma ascensão ao sentido do ser, como meta de seu próprio ensaio.

Tal retorno à filosofia medieval e antiga não pode ser interpretada como a mera assunção de uma atitude dogmática por parte de Edith Stein, ou como um mero esforço para estabelecer as razões da fé, que ela entendeu dever assumir e professar em sua maturidade. Não se deu também por uma atitude de abandono do caminho fenomenológico de pesquisa, que não continha entre seus pressupostos que o fenomenólogo se impusesse a qualquer tarefa de investigação por razões meramente dogmáticas. Era a orientação para a coisa mesma em questão, aquilo que guiava a fenomenologia; e foi a partir desta orientação que Edith Stein foi conduzida a perscrutar os caminhos da investigação filosófica medieval e antiga para desenvolver a sua tentativa de uma ascensão ao sentido do ser.

Edith Stein deixa claro que seu caminho filosófico em direção à filosofia medieval e antiga é fenomenológico. Ela não abandona seu ponto de partida para simplesmente assumir uma posição metafísica. Não há de antemão em Edith Stein um intento de abandonar a fenomenologia em função da assunção de uma doutrina metafísica do ser, elaborada pela tradição. $\mathrm{O}$ diálogo com os antigos emerge em função da própria problemática investigada. Esclarecer como isso ocorre e em que sentido a filosofia platônica e aristotélica entram em jogo em sua busca é a meta deste trabalho.

No Prefácio de Ser finito e ser eterno, Edith Stein explicita que "no ponto médio" de sua investigação "se encontra a questão do ser" (STEIN, 1950, p. IX). E, apesar de ter assegurado que "a confrontação entre o pensamento tomista e o pensamento fenomenológico se constitui no tratamento concreto dessa questão" (STEIN, 1950, p. IX), ela não somente constata a relação que existe entre essa sua obra e aquilo que ela considera "as mais significativas tentativas de uma fundamentação da metafísica em nosso tempo" (STEIN, 1950, p XII)., referindo-se "à Filosofia da Existência de Martin Heidegger e seu contraponto, a Doutrina do Ser de Hedwig Conrad-Martius" (STEIN, 1950, p. 
XII), como também deixa transparecer sua referência aos grandes iniciadores da questão do ser, que foram Platão e Aristóteles.

Aristóteles e Tomás de Aquino é que se tornaram os principais companheiros de caminhada de Edith Stein, mas ela nunca os torna opositores de Platão. Que esta investigação por referência a Platão se torna uma necessidade, Edith Stein deixa entrever mais claramente em sua "visão geral

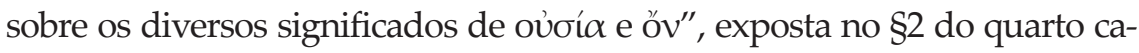
pítulo de Ser finito e ser eterno. Nessa visão geral e esquemática, ela toma a

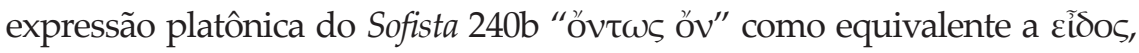
entendendo-a no sentido de ente essencial (Wesenshaftes Seiendes), e assegurando-se de que ela é fundamento de ser (Seinsgrund) e fundamento de essência (Wesensgrund), tanto para o que, no dizer de Aristóteles, é o ente existente ("Oủoí $\alpha=$ Existierendes") como para o que é descrito como o ente

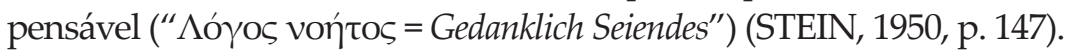

Ora, com base nessa caracterização esquemática, vemos que neste livro Edith Stein assume uma posição a respeito de Platão e Aristóteles que não visa excluir um em detrimento do outro, mas procura uma solução que faça justiça a ambos, em sua investigação a respeito da questão do ser. O problema fundamental, que traz à tona a correlação com Platão e Aristóteles, é o problema da diferença entre ser essente e ser efetivo, que vem discutido no capítulo III de Ser finito e ser eterno e é aprofundado no IV capítulo. Nesses capítulos, deve interessar-nos dois aspectos relevantes, no que diz respeito à filosofia de Platão e Aristóteles no tratamento desse problema da diferença entre ser essente e ser efetivo (wesenhaftes und wirkliches Sein): no terceiro capítulo, importa pensar o que ela diz sobre o modo como pensam Platão e Aristóteles a respeito desse problema; no quarto capítulo faz-se relevante verificar como ela põe a reflexão de ambos em conexão, em sua "visão geral

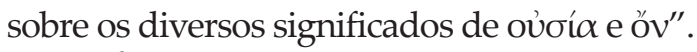

É possível verificar que Edith Stein não entra na discussão considerada tradicionalmente como "metafísica" apenas por uma decisão dogmática. Ela parte da vivência do eu, a fim de compreender que subsiste uma diferença entre o ser real e o ser essencial. Vejamos primeiramente como ela desenvolve esse caminho de compreensão, de modo a podermos também entender como sua virada para a tradição platônico-aristotélica tem por base seu próprio ponto de partida fenomenológico. Em seguida, procuremos 
caracterizar como sua filosofia se orienta numa perspectiva platônico-aristotélica, que faz justiça a ambos, e se mantém na perspectiva de uma filosofia da idealidade que contempla em si o sentido da realidade, constituindo desse modo o ensaio de uma ascensão ao sentido do ser.

\section{A vivência singular como ponto de partida}

O motivo principal, pelo qual se pode verificar que o ponto de partida de Edith Stein permanece fenomenológico, é o fato de que, ao procurar traçar a distinção entre o ser essente e o ser efetivo, Edith Stein toma como ponto de partida a vivência do eu. Este é o ponto de partida estritamente fenomenológico. Tomando como exemplo a vivência de uma alegria, ela exprime claramente a distinção segundo a qual uma coisa é minha alegria, outra coisa é a alegria como tal. Aquela emerge e evanesce. Esta remanesce. Esta distinção a remete ao conceito de

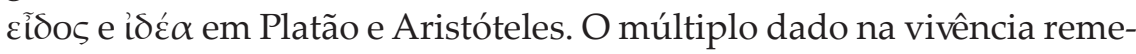
te sempre a uma unidade essencial constituinte dessa multiplicidade.

A essencialidade alegria como una (die Wesenheit Freude als eine) tem o caráter de ser antes, sem ser, porém, no espaço e no tempo. Mas isso também não já quer dizer que tenha que haver um lugar metafísico (isto é, supramundano), ainda que seja pensável como uma região

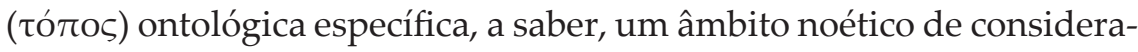
ção do ente, onde ela tenha que ser, já antes de se efetivar como vivência duradoura ou passageira de um indivíduo. Por ser sempre (d̉cí), a essencialidade não está submetida a emergir e evanescer no espaço e no tempo: ela possui o caráter de ser permanente (ḋı́́vıov) ${ }^{3}$.

Essas distinções levam Edith Stein a perceber que aqui está em jogo

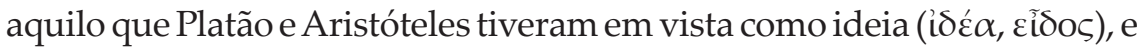
que Edith Stein há de compreender como essencialidade (Wesenheit). "As essencialidades, diz Edith Stein, não são vivências, elas são pressupostos para as unidades de vivência" e se constituem como o compreensível que

3 A partir da filosofia de Aristóteles, é possível compreender que a alegria vivenciada não seria uma прம்tn oủoía por ser uma qualidade no ente e, portanto, não subsiste separadamente. 
constitui o ser do próprio espírito. Diz Edith Stein: “Compreender (intelligere) o compreensível (intelligibile) é o ser mais próprio do espírito; daí ter ele recebido o nome de compreensão (intellectus)" (STEIN, 1950, p. 64). Aqui ela ainda explicita uma diferença que a mim parece muito importante nesse contexto de explicitação da consideração que Edith Stein faz das idealidades, quando ela diz que ratio é compreender em movimento; intellectus é compreensão em repouso.

Neste sentido torna-se também importante notar como ela distingue essencialidade e conceito: essencialidade ( $\varepsilon i \tilde{\delta} \delta \varsigma)$ não é conceito; nós não configuramos essencialidades, nós as deparamos (Wesenheiten bilden wir nicht, sondern finden sie vor). "As essencialidades da vivência não são vivências; elas são pressupostos para as unidades de vivências" (STEIN, 1950, p. 65).

São essas essencialidades que se efetivam, segundo Edith Stein: quando a pura forma assume um conteúdo quididativo, se constitui temporal e espacialmente. Mas: "a efetivação da essencialidade não significa que ela se torna efetiva, mas que algo, que é a ela correspondente, se torna efetivo" (STEIN, 1950, p. 66). Isto é a essencialidade da alegria: é aquilo que faz da alegria, alegria. (Mas dela só se tem notícia pela experiência, pois de um عĩoos só se pode saber pela experiência). Ou seja, esta minha alegria, que se encontra na minha vivência atual, como algo único e temporalmente delimitado, pertence unicamente a mim. Ela é algo, que, correspondendo à essencialidade, se tornou efetivo.

Edith Stein acentua ainda em nota que não é possível, no contexto de sua reflexão em Ser finito e ser eterno, tratar a doutrina platônica das ideias na forma como historicamente se constituiu. Mas todas as questões que são tratadas nessa parte de seu trabalho recaem nesse campo de investigação. Contudo ela nos fornece um esquema que a mim parece extremamente importante para saber em que tipo de conexão ela estabelece Platão e Aristóteles, fazendo justiça a ambos e assumindo uma posição de uma filosofia da idealidade como fundamento constituinte da realidade. 


\section{A virada para a conceituação platônica}

O estabelecimento da idealidade como pressuposto noético da vivência indica no pensamento steiniano uma virada para a posição platônica, que importa ser considerada e exige um esclarecimento. No $\S 2$ do capítulo IV de Ser finito e ser eterno, no qual, de modo esquemático, Edith Stein esboça o que chama de uma "visão geral sobre os diversos significados de oủ $\sigma i ́ \alpha$ e óv", ela deixa entrever a correlação sistemática que ela vislumbra entre Platão e Aristóteles, pelo modo como articula os conceitos fundamentais da filosofia de ambos, numa relação de dependência. Deve-se observar, porém, que é a expressão fundamental platônica óv $\tau \omega \varsigma$ óv $v$ que pode ser tomada como equivalente à expressão aristotélica ôv $\eta$ óv, que é erigida como fundamento do ser efetivo e do sentido inteligível que o determina. $\mathrm{O}$ esquema conceitual é apresentado do seguinte modo:

$$
\text { 'Ov = Ente }
$$

I) Ovंoi $\alpha=$ Existente

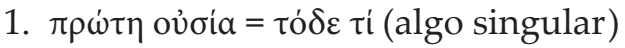

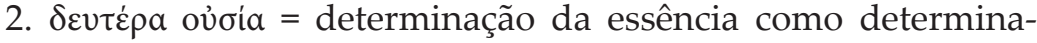
ção quididativa (determinação genérica e específica até à determinação última) $=\tau i$ cĩvaı

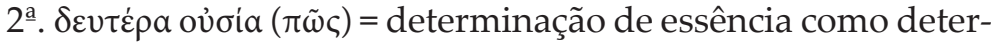

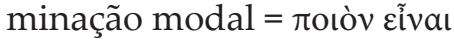

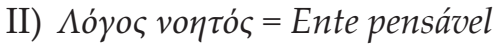

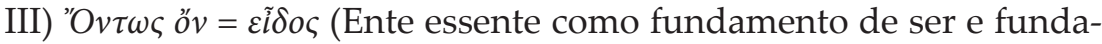
mento de essência para I e II)

1. Essencialidades $=$ Elementos de ser

2. Quididades (Essências quididativas) = Estrutura de sentido coconstituinte

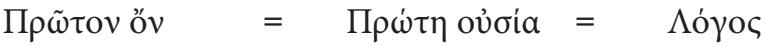

Ente primeiro $=$ Essência-Ser $=$ Sentido

(STEIN, 1950, p. 147) 
Podemos notar que, se, por um lado, o ponto I elenca a conceituação típica da reflexão aristotélica, o ponto três se fixa à conceituação

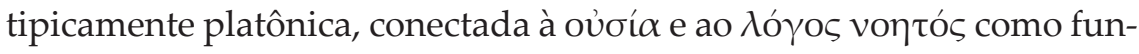

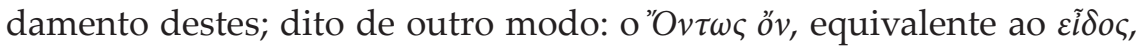
conceitos que exprimem a tópica tipicamente platônica, é compreendido aqui como o fundamento (quiçá enquanto idealidade) da Ov̉oía e do

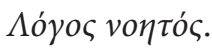

Apesar de desenvolver amplamente a conceituação aristotélica aí em jogo, no capítulo IV, que pretende justamente se ater a uma exposição do conceito de essência enquanto oủoía, Edith Stein não se atém a um esclarecimento do óv $\tau \omega \varsigma$ óv, ipsis literis, e em conexão direta com o pensamento platônico. Mas o عĩosos, como pura forma, é o que é investigado como conceito equivalente ao ǒv $\tau \omega \varsigma$ óv platônico. Contudo, importa perguntar por que o ǒv $\tau \omega \varsigma$ ǒv é, para Edith Stein, equivalente

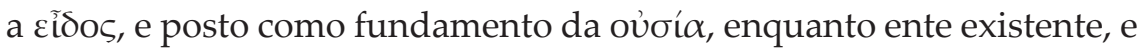

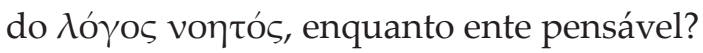

Já pudemos ver, no tópico anterior, como Edith Stein distingue entre a vivência e a essencialidade, à qual a vivência corresponde e que ela, por assim dizer, efetua ou "realiza". A vivência "real" do eu, isto é, como um dado existente, contém em si um conteúdo essencial eidético deparável na vivência, que é uma essencialidade à qual a vivência corresponde e que a vivência pressupõe. Ela é a essencialidade compreensível que constitui o ser do próprio espírito. Mas em que medida esta consideração encontra-se em sintonia com o pensamento platônico? Quais são os elementos do pensamento platônico que dão sustentação a essa consonância e por que, apesar disso, Edith Stein não se ateve a uma exposição detalhada da doutrina das ideias platônica? Será que é porque ela teria optado por um caminho de exposição tipicamente aristotélica e, portanto, reconhecidamente "realista" e não "idealista"? Como se pode entender em Platão a essencialidade como pressuposto noético da vivência?

A expressão őv $\tau \omega \varsigma$ óv emerge no Sofista ( $S p h$.) em conexão íntima com o problema da falsidade do discurso dissimulador do sofista, que leva Platão a pensar em que medida se pode distinguir o modo de ser de um discurso que não leva consigo o caráter que deveria ser próprio 
do discurso, isto é, o caráter de ser verdadeiro e não falso. E tal como ocorre na República (R.) X, é a partir da consideração dos modos de ser em relação ao que verdadeiramente é que Platão coloca o problema da diferença entre o modo de ser do ente como ideia e o modo de ser do ente como imagem. Como compreender o que Platão denomina ǒv $\tau \omega \varsigma$ óv, e por que Edith Stein o considera como fundamento da oủ $\sigma i ́ \alpha$ e do

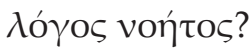

Para ter acesso à compreensão dessa expressão platônica e dos motivos da consideração steiniana a respeito dela, importa que desenvolvamos aqui um pequeno excurso, que leve em conta a consideração platônica dos modos de ser e da busca fundamental do conhecimento como aprendizado daquela essência que sempre é, e que Edith Stein compreenderá como ser essente ou ente essente.

\section{A determinação platônica da idealidade como fundamento do ser efetivo}

A busca pela compreensão do sentido do ser enquanto tal está, em Platão, atrelada à experiência anelante do saber, ao mesmo tempo libertadora, que é própria da filosofia e daquele que se entrega a essa experiência. Ao indivíduo belo e bom entregue a essa experiência convém que, por natureza, possua determinadas qualidades que lhe são essenciais. E a primeira delas é que aquele que anela pelo saber ame, por natureza, aquilo que congenitamente lhe pertence, isto é, a verdade $(\dot{\alpha} \lambda \eta \theta \varepsilon i ́ \alpha \varsigma)^{4}$ (Cf. R. 485c-d).

De acordo com Platão, esta busca há de consistir, porém, em um esforço de voltar-se para o que é, $\pi \rho$ ò tò ôv (Cf. R. 490a 8). Nisto consistiria a tarefa do filósofo por natureza: “Com relação à natureza dos filósofos, devemos aceitar como fato irretorquível que estes são apaixonados do conhecimento capaz de revelar algo daquela essência eterna

4 Faço notar que todas as palavras emergentes no texto platônico e aqui citadas explicitamente, bem como trechos extraídos do texto, foram citadas de acordo com a edição da obra completa de Platão editada por John Burnet (Cf. BURNET, 19001907). 
que não oscila entre o nascimento e a destruição" "5 (NUNES, 2000, p. 278). O filósofo, amante do saber por natureza, é o que ama o aprendizado do que se manifesta como aquela essência que sempre é, dito de outro modo:

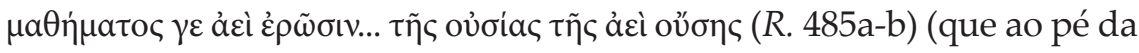
letra significa propriamente: amante do aprendizado... da essência do sempre essente), e não daquilo que se encontra sob a égide da geração e da corrupção, submetido à geração e à corrupção.

É com esta compreensão platônica que Edith Stein entra em consonância quando, tomando como paradigma a vivência concreta de uma alegria, isto é, de um ente efetivo, assegura: "'esta minha alegria' é minha vivência atual, algo único, estabelecido e delimitado temporalmente, pertencente a mim e não a outro" (STEIN, 1950, p. 72). Ou seja, esta minha alegria, que se encontra na minha vivência atual como um fato, como um ser efetivo, como algo único e temporalmente posto e delimitado, pertence unicamente a mim, e, neste sentido, é algo que corresponde à essencialidade alegria, que se tornou efetiva. A alegria vivida é, assim, diz Edith Stein, "uma efetivação da essencialidade alegria" (STEIN,

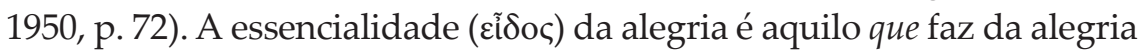
vivenciada uma alegria, ao mesmo tempo em que esta alegria singular é reconhecida tal como uma alegria. "Minha alegria - esta alegria que eu então sinto - emerge e evanesce [entsteht und vergeht]" (STEIN, 1950, p. 61); ou, como diz Platão: "está submetida à geração e à corrupção [ $\pi \lambda \alpha-$

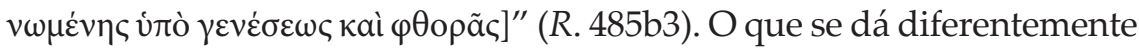

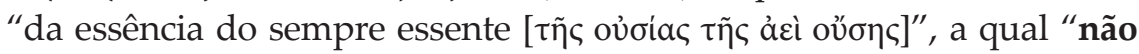

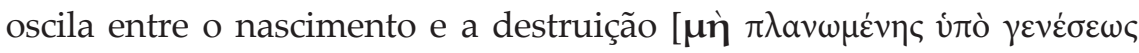
кà $\varphi \theta$ o $a \tilde{c} c]$ " (R. 485b). Ou, como diz Edith Stein: " $a$ alegria como tal não emerge e não evanesce [die Freude als solche entsteht nicht und vergeht nicht]" (STEIN, 1950, p. 61).

Edith Stein reconhece, apesar de não explicitá-las de maneira exaustiva, atendo-se mais a Aristóteles que a Platão, que:

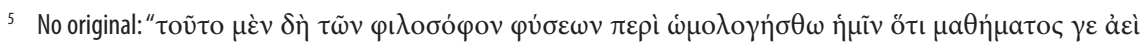

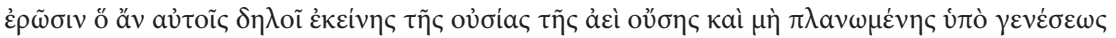
кaì $\varphi \theta$ o $\rho \tilde{c} c^{\prime \prime}($ R. 485a $10-$ b 3). 
Nós topamos, aqui, com uma daquelas construções que Platão tinha em

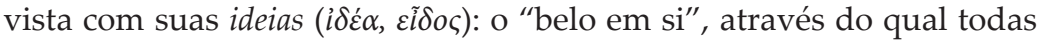
as coisas belas são belas, o "justo em si", através do qual todas as coisas justas são justas, etc. (STEIN, 1950, p. 63).

Edith Stein ressalta, contudo, que não pretendeu utilizar para tais construções a palavra Ideia, digna de tantas controvérsias ${ }^{6}$, mas procurou prioritariamente empregar para tal "a expressão fenomenológica essencialidade" (STEIN, 1950, p. 62). "Em relação com as unidades de vivência, as quais devêm e esvaem", as "essencialidades da vivência" "são, de fato, um ente primeiro" (STEIN, 1950, p. 63-64). Desse modo, elas se constituem a "fonte original do sentido e da compreensibilidade" (STEIN, 1950, p. 64), isto é, a fonte donde emana o sentido

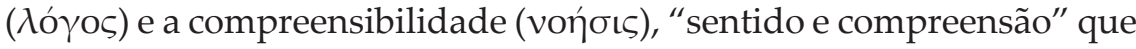
"se pertencem mutuamente" (STEIN, 1950, p. 64).

Daqui se depreende que a i̇đ́c $\alpha$ é, não somente, o pressuposto da vivência efetiva, isto é, daquilo que se perfaz de modo correspondente

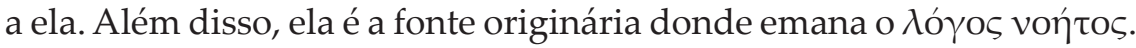
E o ser, que se dignou chamar pelo nome de espírito (Geist, voṽ $)$ ), consiste, segundo Edith Stein, tal como seguramente também para Platão, justamente nisto: "compreender (intelligere) [vocĩ ] o compreensível (intelligibile) [vońtov]; e é por isso, assegura Stein, que ele recebe "daí o nome de compreensão (intellectus) [voũs]" (STEIN, 1950, p. 64).

Por isso que, para Stein, o conhecimento fenomenológico consiste num retorno para a essencialidade, tomando como ponto de partida a vi-

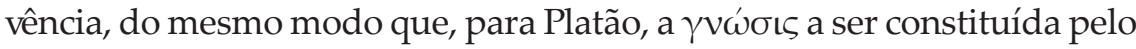
amante do aprendizado consiste num voltar-se para o âmbito inteligível

6 Edith Stein discute já uma primeira vez as controvérsias ligadas ao uso da palavra ideia em conexão com Platão, em seu tratado escrito para fins de habilitação, intitulado Potenz und Akt, quando, ao tentar pensar junto com Tomás de Aquino a questão da "Potencialidade das formas ou espécies", procura discutir a "Problemática das 'ideias", bem como a correlação entre "Ideia e Espírito" (STEIN, 1998, p. 76). Nesse contexto, e apontando para as dificuldades em torno ao conceito de ideia, ela assegura que "já Platão se confrontou com as dificuldades sobre como o termo 'Ideia' há de ser concebido" (STEIN, 1998, p. 77). E para exemplificar situações em que Platão se vê às voltas com esse problema, ela nos remete ao Teeteto 186a e ao Filebo 16c, em que o problema da unidade de uma ideia única ( $\mu$ íav i $\delta \dot{\varepsilon} \alpha v$ ) e da multiplicidade das formas é trazido à tona

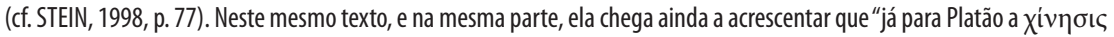

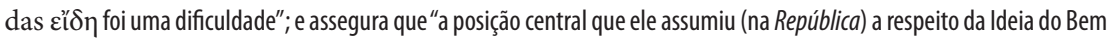
aparece como um protótipo para a concepção agustiniana" (STEIN, 1998, p. 80, n. 1). 
daquela essência sempre essente, que em última instância é, para Platão,

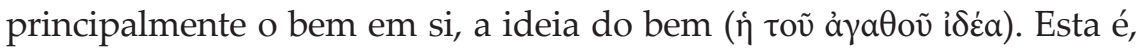

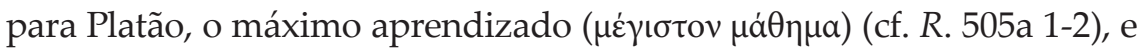

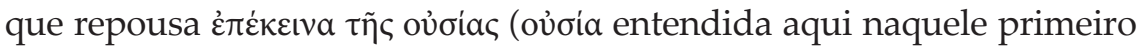
sentido, apontado por Stein em seu esquema conceitual como existente).

Para Platão, essa passagem para o âmbito do conhecimento implicava uma modificação da consideração da consciência ( $\psi v x \eta \dot{)}$ em relação ao ente, que se dirigia do fenômeno do ente para a compreensão de seu ser. Em República VI, a exposição do esquema da linha dividida serviu para mostrar como o ente havia de ser considerado pela $\psi v \chi \eta \dot{n}$, na medida em que a consciência modifica seu modo de apreensão. Enquanto a analogia do sol propõe a diferença e, ao mesmo tempo, a similitude e correspondência dos dois âmbitos de consideração do ente, isto é, o âmbito da aparência visível (fenomênico) e o âmbito do inteligível (noético) (Cf. R. 508b-c) ${ }^{7}$, para caracterizar de que maneira se encontra a ideia do bem em relação ao ente enquanto oủoía (existente), o esquema da linha dividida determina, para cada um desses âmbitos, os atos da consciência ( $\tilde{\varepsilon} \xi \varepsilon$ ) que, ao mesmo tempo, constituem modos como o próprio ente é considerado na relação com ela. Assim, em rela-

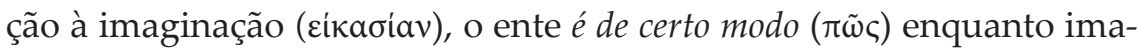

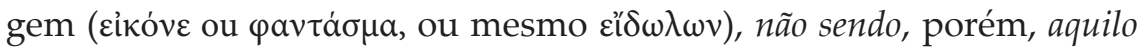

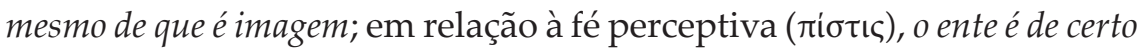
modo como algo que é, mas não propriamente o que é verdadeiramente, uma vez que emerge e evanesce, seja vivente ou produto. Desse modo se caracteriza, no esquema da linha dividida, o âmbito do visível, no qual se constitui um modo de consideração da consciência como certo modo de ser do ente, mas ainda não o ente propriamente.

A passagem para o que é o ente propriamente exige uma penetração da consciência em outro âmbito de consideração, qual seja, o âmbito inteligível, para o qual se constituem os entes matemáticos, que Platão denomina hipóteses (supostos, vi

7 Atente-se para o fato de que, ao considerar 0 ente que se constitui no âmbito do visível e aquele que se constitui no âmbito do inteligível, Platão não está aqui estabelecendo a existência de dois mundos: 0 mundo das ideias e o mundo das coisas

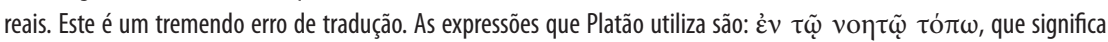

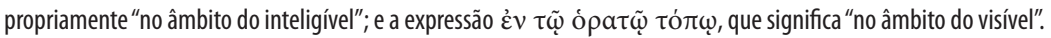


enquanto princípios (ảpxai); assim, o modo de determinação da cons-

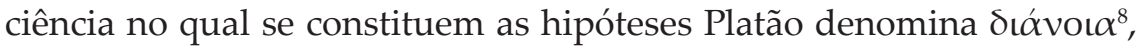
que consiste fundamentalmente em partir de supostos ideativos para deles extrair consequências definitivas, utilizando-se, porém, de imagens que lhes correspondem, fundamentalmente para fins didáticos; por fim, os princípios se constituem e são apreendidos ou pensados

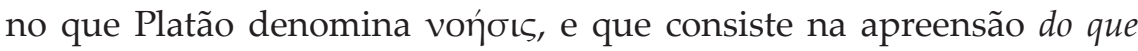
propriamente é, através da consideração das essencialidades puras, para usar o termo preferido por Edith Stein para referir-se às cỉón platônicas.

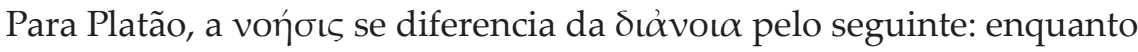
esta se vale de supostos para dela tirar consequências definitivas, utilizando-se de imagens, aquela parte desses mesmos supostos, mas em vista de considerar os princípios não hipotéticos que os fundamentam, sem utilizar-se de imagens, mas apenas de essencialidades (عißń).

Com estas considerações platônicas, presentes em República VI, aproximamo-nos do que Edith Stein denomina e tem em vista propria-

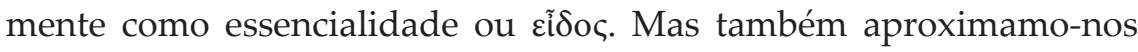
do motivo de caráter platônico porque ela considera o óv $\tau \omega \varsigma$ óv como

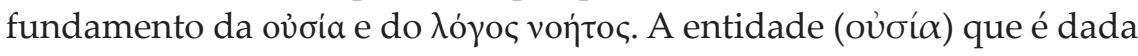
à consciência perceptiva como alegria, por exemplo, não é propriamente a alegria, mas um sentimento que devém e evanesce, correspondente à alegria pensada e sempre essente. A alegria que sinto é, porém, alegria de certo modo: temporalmente determinada, finita, passageira, efetivamente sentida, ainda que não suficientemente pensada naquilo que a constitui: é a alegria para o âmbito de uma consciência sensível. Mas como pensar a essencialidade alegria? Como ela está dada para o pensamento? De que maneira se pode distingui-la como sensível e pensável, como dado evanescente e permanente para a consciência? Claro que a resposta a essa questão exige, em última instância, a determinação de algo que Edith Stein não se propôs a fazer em Ser finito $e$ ser eterno, mas que ela enxerga ter sido um trabalho desenvolvido por

8 Para uma caracterização mais precisa daquilo em que consiste o pensamento dianoético aqui em jogo, encaminho o leitor para 0 meu artigo "0 caráter intermediário da matemática e a de seus elementos segundo Platão e Aristóteles" (SANTOS,

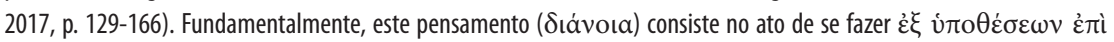

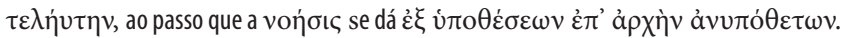


Husserl e que ela pressupõe aqui em seu próprio trabalho. Mas, já que o objetivo desse trabalho é apresentar em que medida tais considerações de Edith Stein remetem-nos à filosofia antiga, perguntemo-nos: de que modo, no pensamento platônico, nós encontramos o caminho para essa fundamentação steiniana, de tal modo que é à expressão óv $\tau \omega \varsigma$ óv platônica que ela recorre como fundamento do ente existente e do discurso do pensamento?

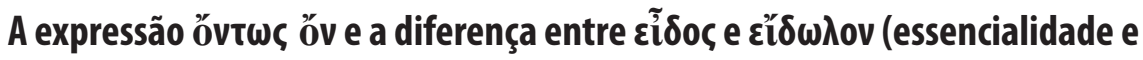

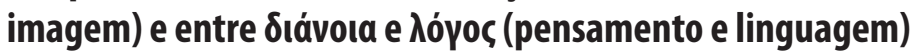

A expressão óv $\tau \omega \varsigma$ ǒv, que emerge no Sofista de Platão, faz parte de um contexto mais amplo. Nesse contexto se inclui a necessidade, que Platão estabelece, seguindo uma tradição que remonta a Heráclito, de tornar claro o papel do filósofo face ao poeta, ao sofista e ao político. Este último chegou a ser considerado no Sofista como um demagogo; o segundo como um dissimulador; e o primeiro como um imitador, tal como já vinha sendo determinado na República X. Nessa caracterização tornou-se fundamental a consideração que chega a diferenciar o

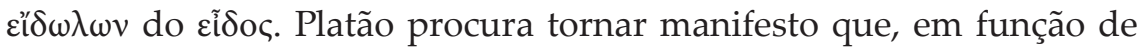
cada um desses modos de ser do ente, está em jogo uma demiurgia específica, considerando divino o responsável pelo عĩos, ao passo que o cilo $\delta \lambda \omega v$ é o que fazem o poeta (em sentido lato), o sofista e o político. Mas o que constitui o modo de ser de cada um desses entes em vista dos quais se estabelece uma demiurgia específica?

Em República X, Platão toma como ponto de partida, tal como Stein o fez em relação ao sentimento de alegria, a diferença que há em se considerar, de um lado, as muitas coisas ( $\pi 0 \lambda \lambda \alpha i$ ) e, de outro, as ideias úni-

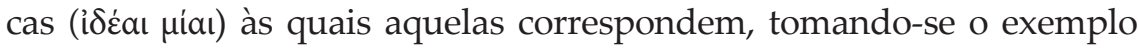
de camas e mesas (cf. R. 596b). Isto quer dizer que, para cada coisa que é, dela há sempre muitos exemplares, porém uma única ideia. Quanto a essas coisas, porém, torna-se patente que são feitas, o que exige um

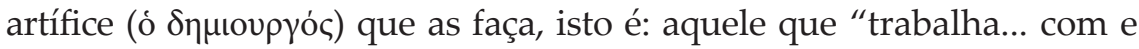
para o $\delta \tilde{\eta} \mu о \varsigma^{\prime \prime}$ (HEIDEGGER, 1961, p. 214), que faz com que as coisas 
se constituam em função do povo, "para a convivência pública e para o uso das coisas” (HEIDEGGER, 1961, p. 214; HEIDEGGER, 2010, p. 166).

$\mathrm{O}$ artífice é inicialmente e em geral artesão ( $\chi \varepsilon\llcorner\rho o \tau \dot{\varepsilon} \chi \nu \eta \varsigma)$ e produ-

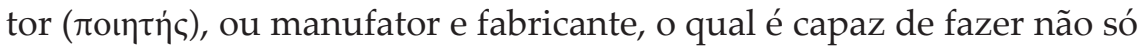
todos os artefatos (cf. R. 596c), mas também tudo o que cresce sobre a terra, e todos os seres animados, as demais coisas e a si mesmo e também a terra, os céus e os deuses, e tudo quanto existe no céu e no subterrâneo (cf. R. 596c 5ss). Mas há que se distinguir de antemão aquele

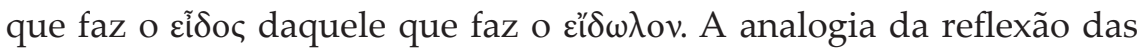
imagens produzidas no espelho é a primeira referência usada para dar

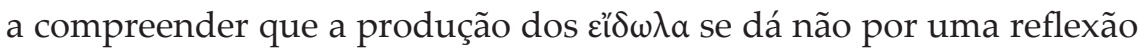
imagética, a partir do que é propriamente, isto é, do ôv, mas a partir do modo como se manifesta a aparência ( aııó $\mu \varepsilon v o v)$ do ente.

Esta analogia da produção de imagens com a reflexão da imagem produzida no espelho abre espaço para a distinção entre três tipos de artífices: o pintor, o artesão e o divino. O pintor não faz a cama, mas sua aparência ( $\varphi$ aıvo $\mu \dot{\varepsilon} v \eta v)$. O manufator ou artesão não faz a essencia-

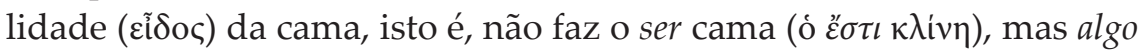

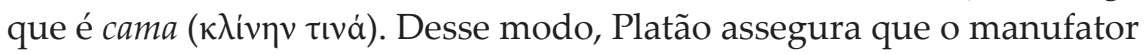

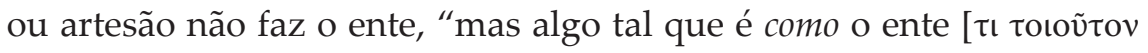

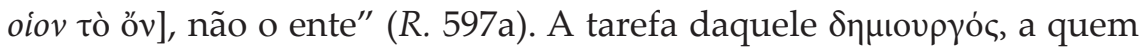
Platão chama propriamente ó $\theta \dot{\varepsilon} \omega \varsigma$ é a seguinte: "fez aquela cama que

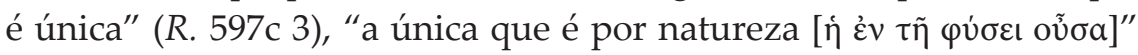
(R. 597 b 5-6). A esta obra desse artífice Platão denomina $\dot{\varepsilon} \varphi v \tau \varepsilon \dot{\theta} \theta \varepsilon \sigma a v$

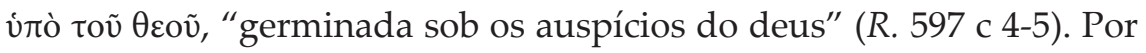

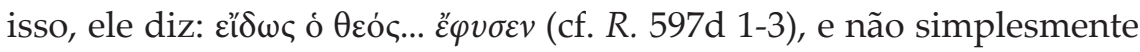

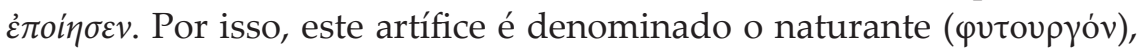
que faz o que é por natureza.

A partir daqui se pode observar como Platão compreende a diferença entre aquilo que a arte mimética em geral tem em vista e aquilo que a filosofia há de ter em vista. Enquanto a filosofia se constitui em

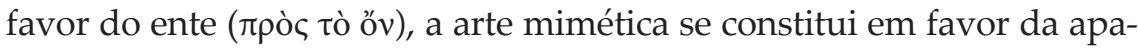

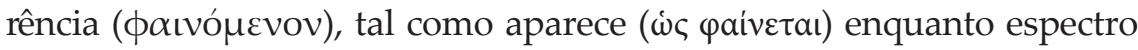

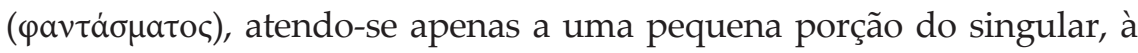
qual se denomina $\varepsilon ` \delta \omega \lambda \omega \nu$ (cf. $R$. 598b 6-8). Edith Stein reconhece essa 
diretiva platônica, mas haverá de discuti-la apenas no capítulo V de Ser finito e ser eterno, no qual trata dos transcendentais e, nesse contexto, da verdade artística (cf. STEIN, 1950, p. 279-284) ${ }^{9}$. O filósofo, porém, que é

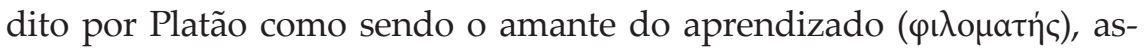
pira (deseja) por natureza a verdade, à luz da qual pode apreender a essência que sempre é (aprendizado da essência do sempre essente); por este amor, o filósofo aproxima-se e afina-se congenitamente pela alma (

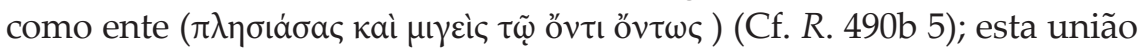

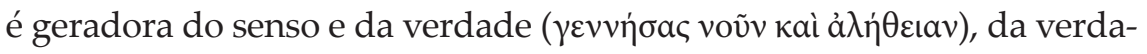
deira vida e do conhecimento ( $\gamma v$ oín $\tau \varepsilon$ kai à $\lambda \eta \theta \tilde{\omega} \varsigma \zeta \tilde{\omega} \eta)$ (Cf. R. 490b 5-6). Aqui já se verifica aquela duplicação terminológica, quando Platão fala do conhecimento do filósofo como uma união com o ente enquanto ente

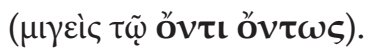

Para entendermos, por fim, como Platão chega à expressão öv $\tau \omega \varsigma$

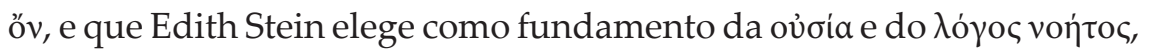
verifiquemos como, no Sofista 240, está em jogo a mesma diferenciação

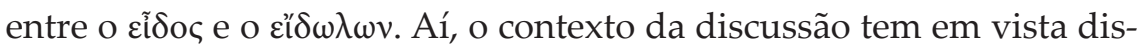
cernir em que consiste o sofista; e, como ficou dito que o sofista nada mais é que um fazedor de imagens ( $\varepsilon i \delta \omega \lambda$ otoı̀vv, "fabricante de simulacros") (Sph. 239d) em vista de uma educação opinativa, ઈó

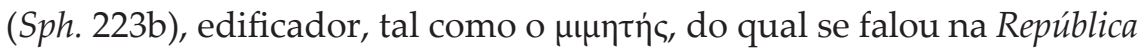

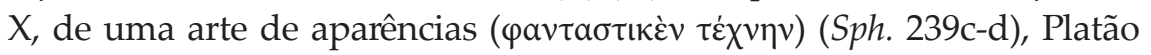

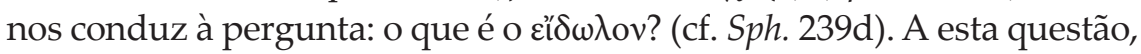
pela boca de Teeteto, personagem do diálogo, Platão responde do seguinte modo: "o que, na verdade, Hóspede, diríamos ser um simulacro, a não ser outra coisa desse tipo", isto é, do tipo do reflexo no espelho ou de uma escultura, "assemelhada ao verídico?" (MURACHCO; MAIA JR.; SANTOS, 2011, p. 207). Então ele expõe pelo que se deve entender

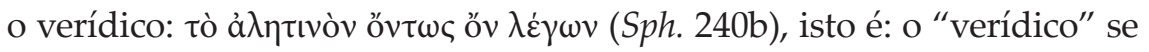
entende por aquilo que "realmente é".

9 Uma análise a respeito da verdade artística na filosofia de Edith Stein, em conexão com o pensamento de Platão e Aristóteles foi desenvolvida em um trabalho apresentado por mim no GT Edith Stein e o Círculo de Göttingen no Encontro da ANPOF de 2016, que deverá sair publicado nos anais ainda este ano. 
Como tal caracterização do عí $\delta \omega \lambda$ ov tivesse conduzido Platão à aporia de falar de algo que não é verdadeiramente como sendo de certo modo, ele nos conduz a pensar o motivo pelo qual o discurso do sofista, como uma imagem fabricada, não é o ente verdadeiramente, e com isso nos ajuda a entender porque o verdadeiro ente enquanto tal é o fundamento não só do discurso verdadeiro como do discurso falso e dissimulador do sofista. E ele nos expõe esse motivo por meio de uma diferença,

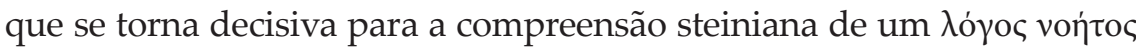
fundado no őv $\tau \omega \varsigma$ šv. Tal exercício de fundamentação pressupõe que se faça uma diferença entre pensamento e linguagem, de tal modo que se compreenda que: não há somente um $\lambda$ ójos constitutivo da natureza e

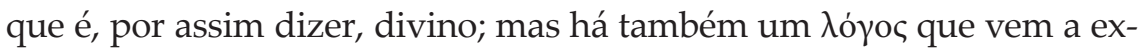
pressão pela fala, o qual, tal como uma imagem sonora, está sujeito a ser utilizado como imagem dissimuladora do que verdadeiramente é.

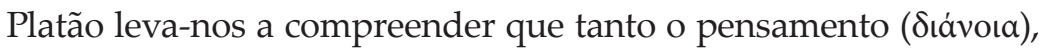
como a opinião ( $\delta$ ó $\xi \alpha)$ e a imaginação ( $\varphi a v \tau \alpha \sigma i \alpha)$, emergem "em nossas almas, tanto como falsos, quanto como verdadeiros" (MURACHCO; MAIA JR.; SANTOS, 2011, p. 252). E o motivo disto é o seguinte (Sph. 263e): "pensamento e discurso são o mesmo; mas o primeiro... é o diálogo íntimo da alma consigo mesma, que nasce sem voz", ao passo que o segundo é "um fluxo a partir da alma, indo através da boca com som" (MURACHCO; MAIA JR.;SANTOS, 2011, p. 253) ${ }^{10}$. No Sofista 264a, a opinião é caracterizada como aquilo que "nasce em silêncio, na alma, com o pensamento", ao passo que a imaginação se constitui "quando, não em si, mas, através das sensações, por sua vez, se faz presente em alguém uma experiência desse tipo" (MURACHCO; MAIA JR.; SANTOS, 2011,

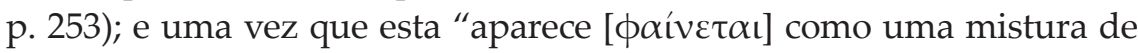

10 Já no Teeteto, 189e, emerge a célebre definição de pensamento, segundo a qual este consiste em "um discurso que a alma mantém consigo mesma, acerca do que ela quer examinar" (NUNES, 2001, p. 107). Aqui, Platão a explicita no intuito de diferenciar pensamento e opinião, colocando na boca de Sócrates, nos passos 189e-190a, que: "é assim que imagino a alma no ato de pensar: formula uma espécie de diálogo para si mesma com perguntas e respostas, ora para afirmar ora para negar. Quando emite algum julgamento, seja avançando devagar seja um pouco mais depressa, e nele se fixa sem vacilações: eis 0 que denominamos opinião. Digo, pois, que formar opinião é discursar, um discurso enunciado, não evidentemente, de viva voz para outrem, porém em silêncio para si mesmo" (NUNES, 2001, p. 107-108). No Sofista 263e, a mesma definição torna a emergir, mas agora não somente no intuito de distinguir pensamento e opinião, mas também o próprio discurso enquanto interior e exterior. Platão também tornará a fornecer uma nova elaboração no Timeu, nos passos 263e-264a. 
sensação e opinião" (MURACHCO; MAIA JR.; SANTOS, 2011, p. 254), o que justifica o fato de um enunciado poder ser dito falso, há imitação de coisas que são e que é a partir deste tipo de imitação que emerge uma "arte do engano" que é própria do sofista (cf. Sph. 264d). Portanto, há um

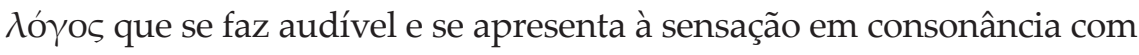
a opinião e o pensamento verdadeiros, mas há também a possibilidade de esse mesmo logos se constituir como uma fantasia enganosa. Em todo caso, isto promove uma divisão da demiurgia, isto é, daquela capacidade de produzir em favor do povo e para a convivência em comum, que se divide em dois tipos de arte produtiva: uma que Platão denomina divina, e outra que o mesmo denomina humana. Tal como em República

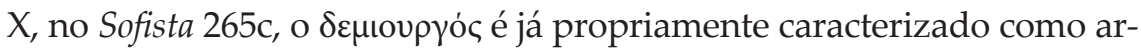

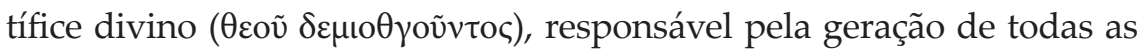
coisas que se constituem por natureza, e não por mero acaso, como se poderia ousar imaginar, revela ser Platão da opinião segundo a qual a

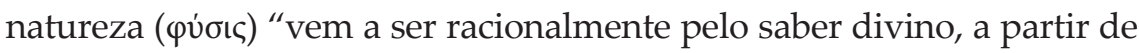
uma divindade"11 (MURACHCO; MAIA JR.; SANTOS, 2011, p. 256).

Há, portanto, uma geração do ente existente que se constitui $\mu \varepsilon \tau \grave{\alpha}$

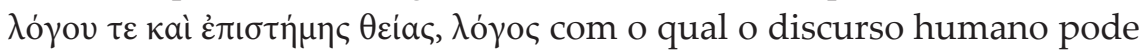
estar em consonância. Esta consonância só se alcança na medida em que o discurso humano se atém às essencialidades, segundo as quais as próprias coisas se constituem. À medida que o verdadeiro ente que é, a essencialidade, se exprime por meio de um $\lambda$ ó $о \varsigma$ a partir do qual

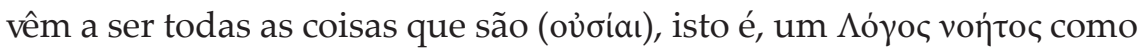

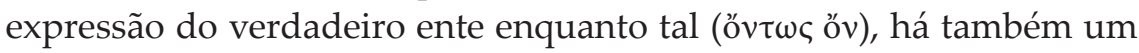
$\lambda$ ójoৎ consonante com esse $\Lambda$ ó $о$ oৎ originário, de acordo com o qual emerge a natureza. Esta é, segundo Edith Stein, "a analogia, a concor-

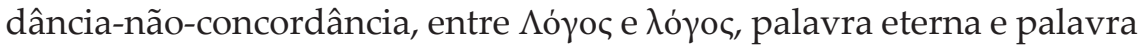
humana" (STEIN, 1950, p. 108); aquela constituindo-se como expressão direta das essencialidades, segundo as quais as coisas se constituem; esta outra, a palavra humana, análoga àquela, e tanto mais passível de lhe corresponder quanto mais penetrar, por meio de uma atitude

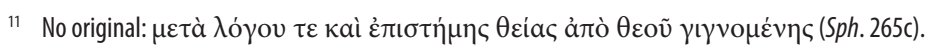


noética, no âmbito das essencialidades, isto é, por meio de uma clarificação eidética das essências.

Mas fato é que Edith Stein não se ateve a fazer uma exposição estritamente platônica dessa analogia, na perspectiva de uma explanação da doutrina das ideias platônica, e faz questão de apresentar os seus motivos. Mas de modo algum isto se deu pelo fato de Edith Stein ter escolhido um caminho de exposição realista e não idealista. Segundo ela, não fora possível, em conexão com seu trabalho, "tratar da Doutrina platônica das Ideias em sua forma histórica" (STEIN, 1950, p. 78, n. 34). Mas acentua que "todas as questões que são levantadas nesta parte" (STEIN, 1950, p. 78, n. 34) do tratado, em que está em jogo a explicitação da distinção e compreensão entre ser essente e ser efetivo, recaem diretamente no campo de estudos desta doutrina (Cf. STEIN, p. 78), e é isto o que esse trabalho pretendeu em linhas gerais mostrar.

\section{Considerações Finais}

Esta consonância do pensamento steiniano com Platão, mas neste sentido também com Aristóteles, ainda que com a ressalva de que, segundo ela, a crítica de Aristóteles às ideias não se aplica de modo algum a Platão mesmo (Cf. STEIN, 1950, p. 98, n. 82), se constitui porque o pensamento de Platão é eidético ou ideativo como nenhum idealismo abstracionista o é; e concreto como nenhum realismo sensualista seria capaz de sê-lo; e o mesmo se deve dizer de Husserl e Edith Stein, tendo sido já mesmo mostrado que o trabalho filosófico de ambos assume o estatuto de um idealismo transcendental (Cf. SAVIAN FILHO, 2017, p. 235), que é, em todo caso e bem compreendido, uma nomenclatura que faz mais jus ao trabalho desenvolvido por ela.

Edith Stein não compreende, porém, que seu trabalho Ser finito e ser eterno se alça a um esclarecimento da constituição ideativa do ente em geral, tal como ela o vê em Husserl, porque não trata até à exaustão do inteligível, propondo-se apenas a "esboçar uma doutrina do ser e não um sistema da filosofia" (STEIN, 1950, p. X). Mas deixa claro que "o fato de que seja examinada em si mesma a doutrina do ser supõe, 
é certo, uma concepção implícita da consciência e da lógica”, as quais "correspondem à estrutura do mundo objetivo" (STEIN, 1950, p. X), e que, ainda segundo ela, "constituem o campo de investigação que E. Husserl designou como objeto da fenomenologia transcendental" (STEIN, 1950, p. X, n. 5).

Por tudo isso, devemos reafirmar, por fim, que Edith Stein não deu um passo metafísico além da fenomenologia que representasse um abandono da fenomenologia transcendental husserliana e a assunção de uma doutrina aristotélico-tomista de caráter dito "realista" e "dogmático". Sua atitude permanece fenomenológica transcendental, bem como se coloca acima de rotulações que põem do lado do idealismo Platão e Agostinho, e do lado do realismo Aristóteles e Tomás. Sua atitude crítica e sistemática se situa aquém dessas rotulações, e coloca o seu trabalho muito mais sintonizado com uma fenomenologia transcendental, para quem a idealidade se impõe como meio fundamental pelo qual a realidade, em todas as suas esferas de consideração, pode vir a ser conhecida.

\section{Referências}

BURNET, I. (Ed.). Platonis Opera I-V. Oxford, 1900-1907.

HEIDEGGER, M. Nietzsche. Erster Band. 1. ed. Günther Neske Pfullingen, 1961.

HEIDEGGER, M. Nietzsche I. Trad. Marco Antônio Casanova. Rio de Janeiro: Forense Universitária, 2010.

KORELC, M. O debate "realismo versus idealismo" em Husserl e Edith Stein. In: MAHFOUD, M.; SAVIAN FILHO, J. Diálogos com Edith Stein: Filosofia, Psicologia e Educação. São Paulo: Paulus, 2017. p. 161-202.

MURACHCO, H.; MAIA JR., J.; SANTOS, J. T. (Ed.). Platão. Sofista. Lisboa: Fundação Calouste Gulbenkian, 2011.

NUNES, C. A. (Ed.). Platão. A República. 3. ed. Belém: EDUFPA, 2000.

NUNES, C. A. (Ed.). Platão. Teeteto/Crátilo. 3. ed. Belém: EDUFPA, 2001. 
SANTOS, G. L. O caráter intermediário da Matemática e o estatuto ontológico de seus elementos segundo Platão e Aristóteles. Archai. Revista sobre as Origens do Pensamento Ocidental, n. 19, jan./abr., p. 129-166, 2017.

SAVIAN FILHO, J. Idealismo e Realismo em Edith Stein. Revista Filosófica São Boaventura, v. 7, n. 1, Curitiba, p. 11-28, 2014.

SAVIAN FILHO, J. Edith Stein para além do debate "idealismo versus realismo": notas de um estudo em construção. MAHFOUD, M.; SAVIAN FILHO, J. Diálogos com Edith Stein: Filosofia, Psicologia e Educação. São Paulo: Paulus, 2017. p. 203-255.

STEIN, E. Endliches und ewiges Seins; Versuch eines Aufstiegs zum Sinn dês Seins. Edith Steins Werke, Band II. Louvain: E. Nauwelaerts; Freiburg: Herder, 1950.

STEIN, E. Potenz und Akt. Studien zu einer Philosophie des Seins. Freiburg; Basel; Wien: Herder, 1998.

Recebido: 02/10/2017

Received: 10/02/2017

Aprovado: 13/10/2017

Approved: 10/13/2017 